\title{
Aspectos anatômicos de plântulas Foeniculum vulgare Mill.
}

\author{
AZEVEDO, C.F. ${ }^{*}$; QUIRINO, Z.G.M. ${ }^{2}$; REGO, E.R. ${ }^{1}$; BRUNO, R.L.A. ${ }^{1}$; SILVA, G.Z. ${ }^{1}$ \\ ${ }^{1}$ Universidade Federal da Paraíba, Centro de Ciências Agrárias, Programa de Pós-graduação em Agronomia, \\ Rodovia PB 097, Km 12, CEP: 58397-000, Areia-Brasil "camfiraze@bol.com.br ²Universidade Federal da Paraíba, \\ Centro de Ciências Aplicadas e Educação, Departamento de Engenharia e Meio Ambiente, Sítio Engenho Novo, s/n, \\ CEP: 58280-000, Mamanguape-Brasil
}

RESUMO: A erva-doce, Foeniculum vulgare Mill. (Apiaceae), é uma erva entouceirada, aromática que apresenta propriedades condimentares e medicinais; tem origem Européia e é amplamente cultivada em todo o Brasil. Devido à deficiência de informações relativas à organização estrutural de plântulas de espécies medicinais, o presente estudo teve como objetivo fornecer informações sobre a anatomia e o desenvolvimento de plântulas de $F$. vulgare. As sementes de erva-doce foram semeadas em areia e mantidas em casa de vegetação por 25 dias, sendo realizadas regas diárias. Foram selecionadas plântulas normais e de padrão uniforme, que tiveram raiz, zona de transição, caule, cotilédones e primeiras folhas seccionados à mão livre. Este material foi corado e montado em lâminas com glicerina para observação em microscópio. Em todos os órgãos da plântula de erva-doce a epiderme é unisseriada, cuticularizada e com estômatos; sendo que as duas últimas estruturas não são encontradas na raiz, porém esta apresenta pêlos unicelulares e cônicos. Os cotilédones e as folhas apresentam funções fotossintéticas e nutricionais, indicadas pela presença de grande quantidade de estômatos, cloroplastos e amido. A caracterização anatômica de plântulas de $F$. vulgare auxilia na identificação da espécie e no conhecimento da organização celular, fornecendo informações que auxiliam em estudos fisiológicos, taxonômicos e ecológicos.

Palavras-chave: Foeniculum vulgare Mill., erva-doce, germinação, identificação de plântulas

ABSTRACT: Anatomical aspects of the Foeniculum vulgare Mill. seedling. Fennel, Foeniculum vulgare Mill. (Apiaceae), is a forming clumps herb and presents aromatic, medicinal and condimental properties. It has European origin and is widely cultivated and used in Brazil. Due to lack of information concerning the structural organization of seedlings of medicinal species, this study aimed to provide information about the anatomy and development of $F$. vulgare seedlings. The seeds fennel was sowed in sand and maintained in greenhouse for 25 days, with daily waterings. Were selected normal seedlings and with patterns uniforms, for freehand seccion of root, transition zone, stem, cotyledons and first leaves. This material was stained and mounted on slides with glycerol for observation under microscope. In all the parts of seedling fennel the epidermis is uniseriate, with a cuticle and stomata, and the two latter structures are not found in the root, but has tapered hairs unicellular. The cotyledons and the leaves have photosynthetic and nutrition functions, as indicated by the presence of large numbers of stomata, chloroplast and starch. The anatomical characterization of the $F$. vulgare seedling aids in specie identification and knowledge of cellular organization, providing information that assists in physiological, taxonomic and ecological studies.

Key words: Foeniculum vulgare Mill., fennel, germination, seedlings identification

\section{INTRODUÇÃO}

A erva-doce é uma oleaginosa cultivada de grande importância econômica e medicinal no Brasil. Porém, existem algumas espécies morfologicamente similares, dificultando a identificação (Pimenov \& Leonov, 2003). Simões et al. (2004) citam a semelhança entre Foeniculum vulgare e Pimpinella

Recebido para publicação: setembro de 2011

Aceito para publicação: março de 2012

Rev. Bras. Pl. Med., Botucatu, v.14, n.esp., p.197-204, 2012. 
anisum L., que são conhecidas como erva-doce.

F. vulgare, pertencente à família Apiaceae (Umbelliferae), também é chamada de funcho, falsaerva-doce e anis-doce. É aromática e apresenta porte baixo com $40-90 \mathrm{~cm}$ de altura; com folhas inferiores alargadas podendo atingir até $30 \mathrm{~cm}$ de comprimento e folhas superiores mais estreitas, com pecíolo alargado e folíolos reduzidos a filamentos. Possui a inflorescência em forma de umbela composta por 1020 umbelas menores, com flores pequenas, hermafroditas e de cor amarela. Os frutos são oblongos, compostos por dois aquênios com cerca de $4 \mathrm{~mm}$ de comprimento (Oliveira et al., 2005; Lorenzi \& Matos, 2008), sendo considerados como fruto-semente.

A erva-doce é originária da bacia do mediterrâneo oriental e do Cáucasio sendo atualmente cultivada sob numerosas variedades; foi trazida para o Brasil na época da colonização (Simões et al., 2004) e destaca-se por possuir propriedades aromáticas, condimentares e medicinais. Segundo Von Hertwig (1991), os frutos, as raízes e as folhas frescas, são as partes mais utilizadas para fins terapêuticos. Essa cultura também é de grande importância para a indústria cosmética, por possuir óleo essencial utilizado na produção de sabonetes, hidratantes e perfumes.

Mesmo existindo trabalhos que enfatizam a utilização de extratos em ensaios biológicos, sendo uma espécie com grande potencial de uso medicinal, além de uso na indústria cosmética e por representar importante fonte de renda para os produtores, poucas pesquisas foram realizadas com enfoques anatômico e fisiológico com a espécie $F$. vulgare (Bernath et al., 1996; Sousa et al., 2005), além disso, também são escassas as pesquisas com anatomia de plântulas com a família Apiaceae (Pütz \& Sukkau, 2002; Hackbart \& Cordazzo, 2007), bem como com outras espécies medicinais.

Tendo em vista estas considerações, o presente estudo teve como objetivo fornecer informações sobre a anatomia e o desenvolvimento da plântula de $F$. vulgare.

\section{MATERIAL E MÉTODO}

O trabalho foi realizado no Laboratório de Análise de Sementes do Departamento de Fitotecnia do Centro de Ciências Agrárias - UFPB, em Areia; com plântulas provenientes de sementes coletadas num campo experimental, localizado na fazenda Boa Sorte no município de Montadas-PB.

Cerca de 50 sementes foram semeadas a 1 $\mathrm{cm}$ de profundidade, em bandejas plásticas contendo o substrato areia, umedecida a $60 \%$ da capacidade de acordo com as Regras para Análise de Sementes RAS (Brasil, 2009). As bandejas foram mantidas em casa de vegetação por 25 dias, sendo realizadas regas para a manutenção da umidade. Foram selecionadas plântulas normais e de padrão uniformes, com 25 dias, para as análises microscópicas e macroscópicas, realizadas com material in vivo e conservado em álcool a $70 \%$. Foram consideradas normais aquelas plântulas que apresentaram características condizentes com as prescritas pelas RAS (Brasil, 2009).

Partes das plântulas (raiz, zona de transição, caule, cotilédones e primeiras folhas) foram selecionadas para análises posteriores em laboratório através de observação direta. O material selecionado foi seccionado à mão livre com lâmina de barbear, utilizando-se pecíolo de embaúba como suporte e hipoclorito de sódio a $1 \%$. Utilizou-se como corante safranina a $10 \%$, azul de metileno a $10 \%$ e o reagente para amido lugol, na análise de algumas secções. $O$ material foi montado em lâminas semi-permanentes, com glicerina, e observado em fotomicroscópio.

A contagem dos estômatos foi realizada utilizando-se secções paradérmicas de todos os órgãos, exceto da raiz, e tendo como base $1 \mathrm{~mm}^{2}$. Para a contagem dos grãos de amido nos cotilédones e nas folhas, foram utilizadas secções transversais e usou-se como base $10 \mu \mathrm{m}^{2}$. A contagem dos cloroplastos foi feita calculando-se a média dos cloroplastos presentes nas células-guardas de cinco estômatos escolhidos aleatoriamente, na folha e no cotilédone. Estas análises foram feitas utilizando-se quatro plântulas, onde cada uma representou uma repetição (calculada pela média de cinco contagens); e o resultado final foi dado pela média das repetições.

\section{RESULTADO E DISCUSSÃO}

A raiz de $F$. vulgare é ramificada e apresenta epiderme unisseriada e irregular, onde são encontrados pêlos unicelulares, cônicos e de parede delgada, restritos à base radicular não ocorrendo em regiões próximas ao ápice (Figura 1a). Nas plântulas em geral, esses pêlos comumente se restringem a uma região da raiz, localizada a poucos centímetros do ápice (Esau, 1977) e aumentam significativamente a área de superfície radicular, potencializando a função de absorção (Taiz \& Zeiger, 2009).

O córtex é formado por 4-5 camadas de células de tamanhos irregulares, onde ocorre principalmente parênquima, com endoderme apresentando estrias de Caspary (Figura 4b). $O$ desenvolvimento dessas estrias é seguido pela deposição de uma lamela de suberina, que tem a função de defesa contra microorganismos (Cutter, 1986; Esau, 1998), impedindo a difusão de água através das paredes celulares; dessa forma, a água tem que atravessar o protoplasma das células, o que reduz a perda de água para o solo (Fahn, 1990).

No cilindro central ocorrem periciclo e

Rev. Bras. PI. Med., Botucatu, v.14, n.esp., p.197-204, 2012. 
tecidos vasculares primários e secundários, apresentando dois pólos protoxilemáticos estreitos e metaxilema entre esses pólos, caracterizando-a de diarca (Figura 1c); porém a raiz apresenta desenvolvimento consideravelmente maior, ao se aproximar da zona de transição (Figura 1b); caráter também observado em outras espécies, como Dahlstedtia pinnata (Benth.) Malme. (Teixeira \& Gabrielli, 2000), Solanum sisymbriifolium Lam. (Hadid et al., 2007) e Gevuina avellana Mol. (Ramirez et al., 2004). Entre o protoxilema e o periciclo encontra-se o floema primário, onde são encontradas gotículas de óleo (Figura 1d), que assim como outras substâncias, afirmam Ramirez et al. (2004), funciona como reserva e ajudam a nutrir a planta, principalmente em solos pobres em nutrientes.

A zona de transição é revestida por epiderme unisseriada de aproximadamente $2,75 \mu \mathrm{m}$ de espessura, formada por células justapostas e alongadas, e uma camada externa de cutícula de suberina, medindo cerca de $0,6 \mu \mathrm{m}$. São encontrados 21-28 estômatos paralelocíticos por $\mathrm{mm}^{2}$, com diâmetro polar de $4,8 \mu \mathrm{m}$ e equatorial de $2,0 \mu \mathrm{m}$ (Figuras 1e e g). O córtex é composto de cerca de sete camadas de células parenquimáticas, circundando o feixe vascular (Figuras $1 \mathrm{f} \mathrm{e} \mathrm{h}$ ).

Alguns autores denominam a zona de transição entre a raiz e o caule de hipocótilo (Melo et al., 2004; Souza \& Oliveira, 2004; Batillani et al., 2007; Souza et al., 2007; Ortolani et al., 2008), porém esta estrutura pode ser muito complexa e existem muitas variação nas regiões de transição dos diferentes tipos de plantas (Esau, 1998; Raven et al., 2001) e muitas vezes, a modificação do sistema vascular só é visualizada através de cortes anatômicos, sendo muito difícil a determinação visual do hipocótilo.

Dessa forma, o conceito de região de transição é aceito por vários anatomistas (Mauseth, 1988; Fahn, 1990; Esau, 1998). Esau (1977) considera a zona de transição na plântula como estrutura separada, agregada à raiz e aos cotilédones, apesar do sistema vascular da raiz e cotilédones ser uma unidade desde as primeiras etapas da embriogenia; assim como ocorre com a espécie em estudo.

O caule apresenta epiderme uniestratificada e cuticularizada, com células de formato semelhante às encontradas na zona de transição; porém no caule, a cutícula e a epiderme são mais delgadas, com $0,30 \mu \mathrm{m}$ e 2,17 $\mu \mathrm{m}$ de espessura, respectivamente (Figura 2a). São encontrados de 26-35 estômatos paracíticos e diacíticos, com diâmetro polar de 2,55 $\mu \mathrm{m}$ e equatorial de 1,52 $\mu \mathrm{m}$ (Figuras $2 \mathrm{c} \mathrm{e} \mathrm{d}$ ).

$O$ córtex é estreito e formado por cerca de três camadas de parênquima clorofiliano (Figuras 2a e $7 b$ ), exceto na região externa aos feixes vasculares, onde encontram-se 3-4 camadas de colênquima, intimamente ligadas às células da epiderme (Figura 2b). Abaixo desses tecidos encontram-se várias camadas de células parenquimáticas.

O caule apresenta estrutura correspondente ao pecíolo foliar, com três feixes vasculares pouco desenvolvidos, onde o floema é externo ao xilema helicoidal (Figura 2f) e contêm, na proximidade e em cada feixe, um canal secretor arredondado formado
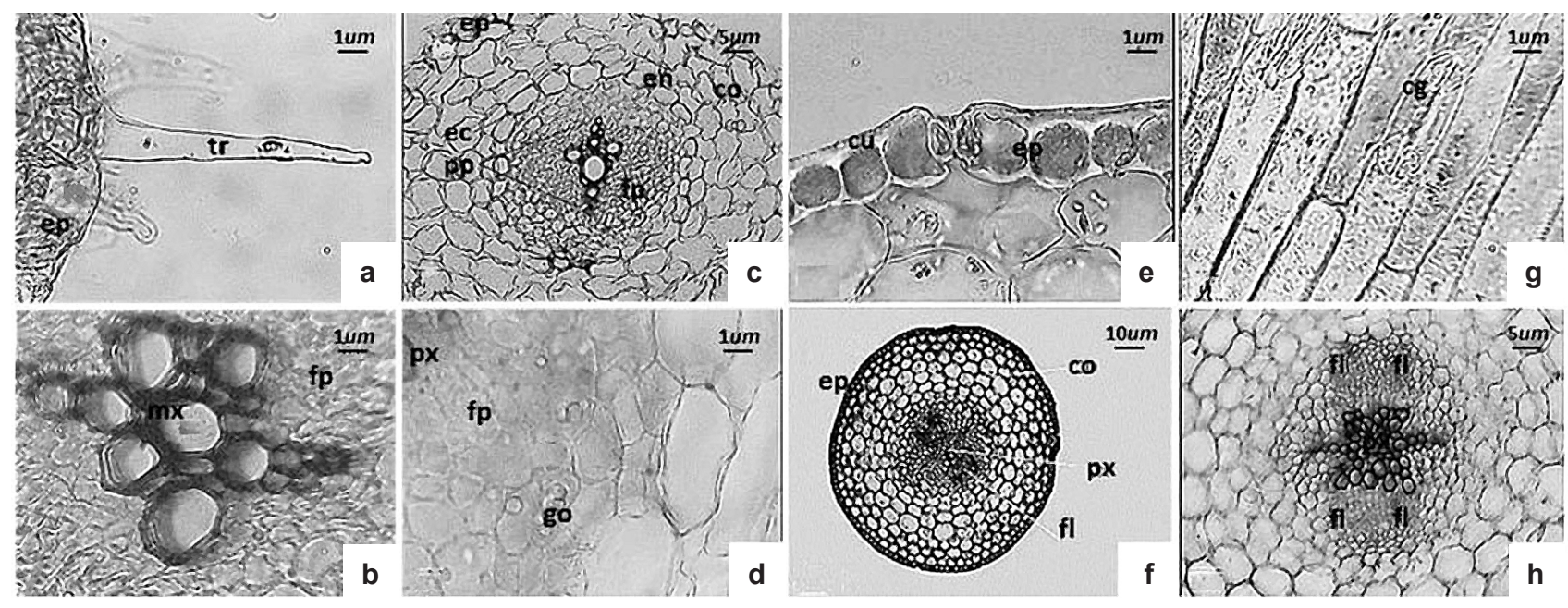

FIGURA 1. Raiz e zona de transição da plântula de Foeniculum vulgare Mill. a. secção transversal evidenciando tricoma. b. desenvolvimento do protoxilema. c. secção transversal mostrando as estruturas da raiz, com dois pólos protoxilemáticos. d. região do floema contendo gotículas de óleo. e. secção transversal da região da epiderme. f. secção tranversal mostrando a estrutura geral. g. secção paradérmica da epiderme evidenciando estômato paralelocítico. $\mathbf{h}$. região do cilindro central. $(\mathrm{tr}=$ tricoma; $\mathrm{ep}=$ epiderme; $\mathrm{mx}=$ metaxilema; ec $=$ estrias de Caspary; $\mathrm{pp}$ = pólos protoxilemáticos; $\mathrm{co}$ = córtex; $\mathrm{fp}$ = floema primário; en = endoderme; go = gotículas de oleo; $\mathrm{cu}$ = cutícula; $\mathrm{cg}$ = célula-guarda; $\mathrm{px}$ = protoxilema; $\mathrm{fl}$ = floema).

Rev. Bras. Pl. Med., Botucatu, v.14, n.esp., p.197-204, 2012. 


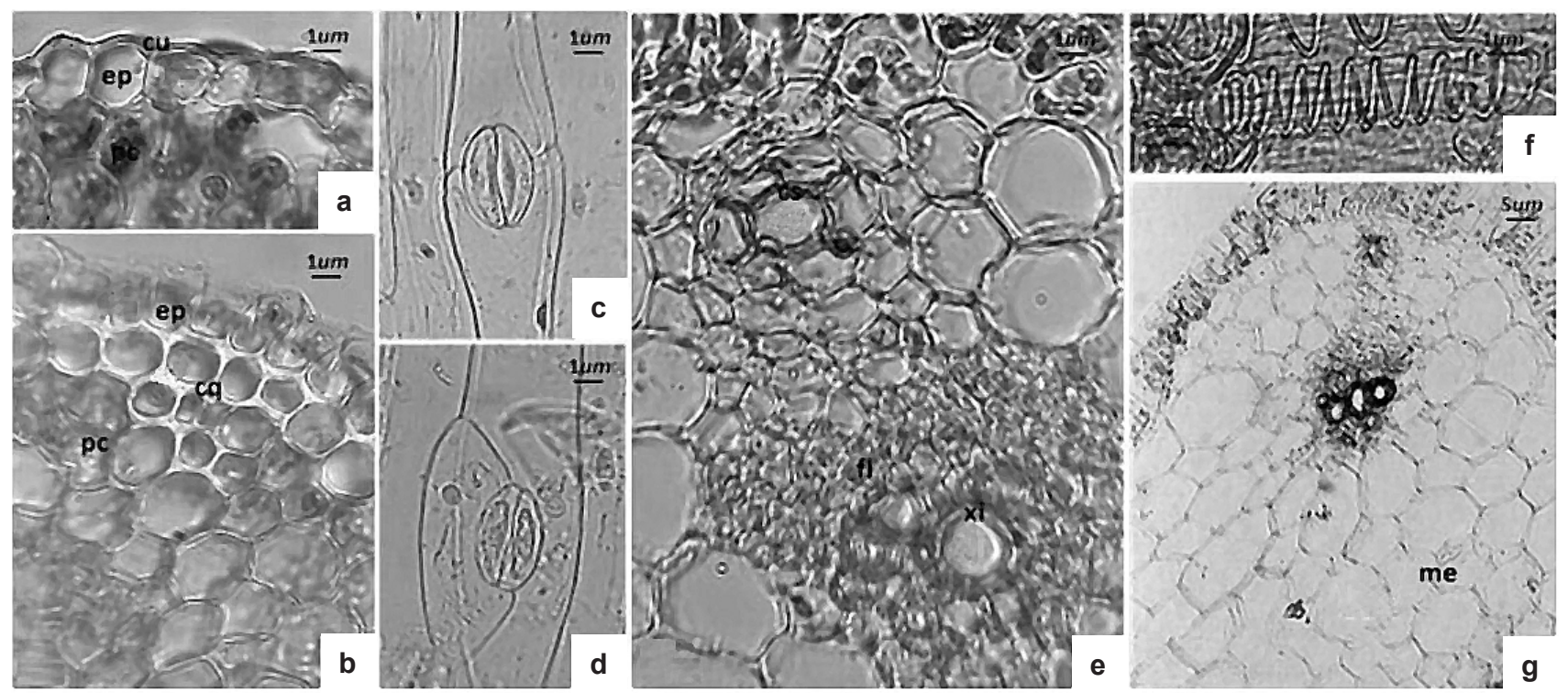

FIGURA 2. Caule da plântula de Foeniculum vulgare Mill. a. secção transversal mostrando a epiderme e o parênquima clorofiliano. b. região do colênquima. c. estômato diacítico. d. estômato paracítico. e. secção transversal do feixe vascular, evidenciando o canal secretor, floema e xilema. f. xilema helicoidal. g. feixe vascular e medulla. (cu = cutícula; $\mathrm{ep}=$ epiderme; $\mathrm{pc}=$ parênquima clorofiliano; $\mathrm{cq}=$ colênquima, $\mathrm{cs}$ = canal secretor; $\mathrm{fl}=\mathrm{floema} ; \mathrm{xi}=$ xilema; me = medula).

por 5-6 células circulares (Figura 2e). No centro existem várias camadas de células parenquimáticas grandes, de tamanhos irregulares e paredes delgadas, formando a medula (Figura 2g). Canais secretores são encontrados nos frutos da mesma espécie (Oliveira et al., 2005) e em plântulas de várias outras espécies medicinais, como Sterculia striata A. StHil. \& Naudin (Gonzalez \& Cristóbal, 2006), Eupatorium rugosum Houtt., Conyza canadensis (L.) Cronquist (Arias, 2005), Myracrodruon urundeuva Fr. Allem (Carmello-Guerreiro \& Paoli, 1999a) e Schinus terebinthifolius Raddi (Carmello-Guerreiro \& Paoli, 1999b). Onde normalmente são secretados produtos de composição química variada, a exemplos de água, soluções salinas, óleos, mucilagens, gomas, proteínas, resinas, entre outros, sendo que a natureza do material depende da espécie e do local da planta (Apezzato-da-Gloria \& Carmello-Guerreiro, 2003).

O limbo cotiledonar, em secções transversais e paradérmicas, apresenta epiderme unisseriada nas faces adaxial e abaxial, com cerca de 3,40 e 2,45 $\mu \mathrm{m}$ de espessura, respectivamente (Figura 3 ). Na face adaxial as células são de formatos diferentes, bem como na face abaxial; porém, nesta última, as paredes celulares apresentam-se bem mais sinuosas (Figuras $3 \mathrm{c}$ e d). Nas duas faces do mesofilo encontrase um revestimento externo de cutícula de suberina, de $0,50 \mu \mathrm{m}$ de espessura na adaxial e de $0,42 \mu \mathrm{m}$ na face abaxial (Figuras 3a e c). A cutícula é extremamente resistente aos micoorganismos, proporcionando proteção mecânica e contra infecções por patógenos (Cutter, 1986).
São encontrados estômatos anomocíticos em ambas as faces do mesofilo do cotilédone, sendo envolvidos por um número variável de células de formato e tamanho diferentes das demais células epidérmicas (Figuras $3 \mathrm{~b}$ e d); características também observadas em outras espécies medicinais com o mesmo tipo estomático, como Schinus terebinthifolius Raddi e Myracrodruon urundeuva Allemão (Duarte et al., 2009). Tais estômatos também ocorrem em Hydrocotyle umbellata L., outra espécie da família Apiaceae (Martins et al., 2008).

$\mathrm{Na}$ epiderme da face adaxial foram encontrados aproximadamente 50 estômatos por $\mathrm{mm}^{2}$ com 10 cloroplastos cada, $3,47 \mu \mathrm{m}$ de diâmetro polar e 2,30 $\mu \mathrm{m}$ de diâmetro equatorial (Figura 3b); já na face abaxial existem cerca de 122 estômatos por $\mathrm{mm}^{2}$ com 14 cloroplastos cada, apresentando 4,10 $\mu \mathrm{m}$ de diâmetro polar e $2,40 \mu \mathrm{m}$ de diâmetro equatorial (Figura 3d). Dessa forma, como é encontrado número bem maior de estômatos na epiderme abaxial, contendo maior quantidade de cloroplastos, confirmase a eficiência fotossintética deste tecido e do parênquima esponjoso subsequente. Essa alta eficiência também ocorre em outras espécies de cotilédones foliáceos, cuja função principal é a fotossíntese (Moreira-Coneglian \& Oliveira, 2006). Em cotilédones fotossintetizantes encontra-se menor quantidade de estômatos na face abaxial (Kitajima, 1992), já em folhas anfiestomáticas, a frequência de estômatos é menor na face adaxial (Mott et al., 1982). Dessa forma, observa-se que nas plântulas de ervadoce, o número relativo de estômatos nas faces

Rev. Bras. PI. Med., Botucatu, v.14, n.esp., p.197-204, 2012. 


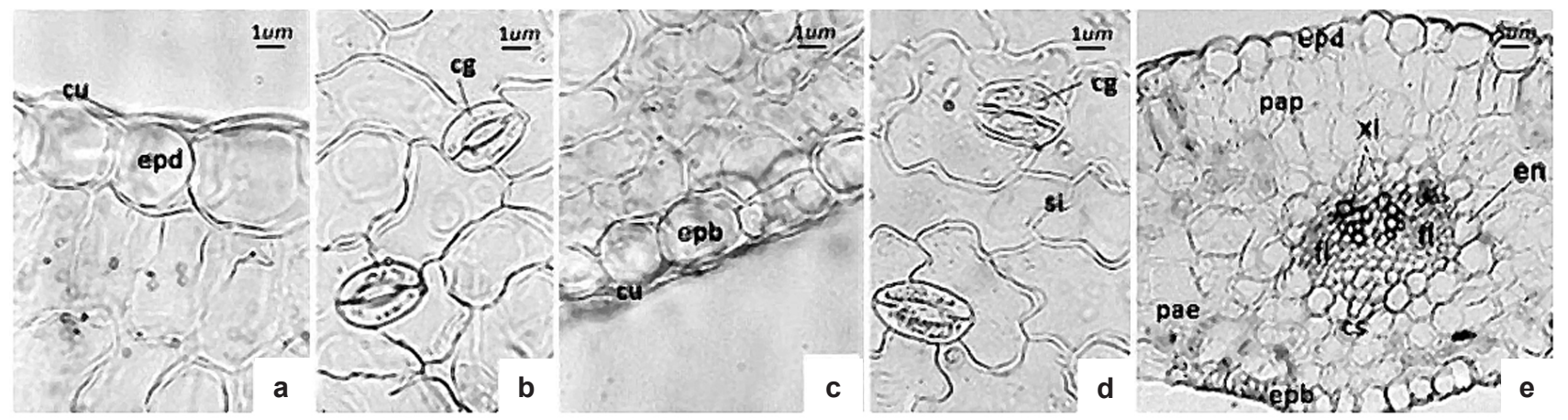

FIGURA 3. Cotilédone da plântula de Foeniculum vulgare Mill. a. secção transversal da epiderme adaxial. b. secção paradérmica da epiderme adaxial. c. secção transversal da epiderme abaxial. $\mathbf{d}$. secção paradérmica da epiderme abaxial. e. secção transversal da nervura central. (cu = cutícula; epd = epiderme adaxial; epb = epiderme abaxial; $\mathrm{cg}$ = célula-guarda; $\mathrm{si}$ = sinuosidades; pap = parênquima paliçádico; pae = parênquima esponjoso; $\mathrm{fl}=$ floema; $x i=$ xilema; $c s$ = canal secretor; en = endoderme).

cotiledonares se assemelha mais aos encontrados em folhas e menos aos encontrados em cotilédones; outra característica que confirma a eficiência fotossintética desses cotilédones.

O mesofilo cotiledonar é clorofilado, apresentando parênquima paliçádico apenas na face adaxial, formado por único estrato de células isodiamétricas e retangulares, em vista transversal (Figura 3e). O parênquima esponjoso é denso, está voltado para a epiderme abaxial e contém de 5-6 camadas de células justapostas de formatos variados, desde quadrangular até circulares (Figura 3e).

Nos cotilédones em estudo, além da função fotossintética, também observou-se a função de reserva, pois são encontrados de $38-45$ grãos de amido por $10 \mu \mathrm{m}$, distribuídos por todo o mesofilo (Figura 3e). Embora a principal função de cotilédones foliáceos seja a fotossíntese, existem outras espécies, assim como a erva-doce, que também apresentam grãos de amido nesse órgão (Mourão et al., 2002; Martine et al., 2008).

A vascularização cotiledonar é feita por feixes vasculares colaterais imersos no mesofilo, encontrando-se dois feixes vasculares nas periferias do cotilédone, formando as nervuras secundárias e um feixe vascular na região central mais desenvolvido, formando a nervura central (Figura 3e).

A nervura central do cotilédone é biconvexa, sendo mais pontiaguda na face adaxial. Encontra-se dois a três pontos principais de xilema helicoidal voltado para a região adaxial; e posteriormente, existem várias camadas de floema lateralmente ao xilema. Abaixo deste xilema, entre os dois pontos de tecido floemático, encontra-se um canal secretor delimitado por células circulares (Figura $3 e$ ). O feixe vascular é envolvido pela endoderme e, externamente, pelos mesmos tipos de células que formam o mesofilo. As nervuras secundárias apresentam padrão semelhante à central, com xilema seguido por floema, onde encontra-se um ducto secretor; porém, o xilema e o floema estão restritos a apenas uma região. Canais secretores também são encontrados em cotilédones de outras espécies produtoras de óleos, como em Eucalyptus phoenicea, E. nesophila e E. brachyphylla (Cutter, 1986).

As primeiras folhas das plântulas são anfiestomáticas, possuem epiderme uniestratificada e cuticularizada em ambas as faces, formada por células de paredes delgadas, sinuosas e convexas (Figura 4); sendo que esta última, segundo Taiz \& Zeiger (2009), é uma característica que potencializa a captação de luz. Além da função que aumenta a capacidade fotossintética, Moreira-Coneglian \& Oliveira (2006) afirmam que as células epidérmicas, desenvolvendo sinuosidades, apresentam aumento da superfície de contato entre células, ampliando a resistência do sistema dérmico e a eficiência na transferência de substâncias célula a célula.

A epiderme adaxial tem cerca de $2,9 \mu \mathrm{m}$ de espessura e cutícula de $0,25 \mu \mathrm{m}$, onde são encontrados 68 estômatos anomocíticos por $\mathrm{mm}^{2}$ contendo aproximadamente 16 cloroplastos nas células-guardas; o diâmetro polar de cada estômato é cerca 3,21 $\mu \mathrm{m}$ e o equatorial é de 2,10 $\mu \mathrm{m}$ (Figuras 4a e c). Já a epiderme abaxial mede $2,42 \mu \mathrm{m}$ de espessura e a cutícula, 0,40 $\mu \mathrm{m}$, onde são encontrados em torno de 111 estômatos por $\mathrm{mm}^{2}$, também anomocíticos, que apresentam em torno de 20 cloroplastos nas células-guardas; o diâmetro polar é cerca de 3,12 $\mu \mathrm{m}$ e o equatorial é de 1,90 $\mu \mathrm{m}$ (Figuras $4 \mathrm{~b}$ e d).

A quantidade maior de estômatos na epiderme abaxial também ocorre em folhas adultas de outras espécies da família Apiaceae já estudadas, como Hydrocotyle umbellata L. (Martins et al., 2008) e Cunila microcephala Benth. (Toledo et al., 2004); indicando o início da formação morfofuncional das primeiras folhas de erva-doce. Taiz \& Zeiger (2009) explicam que a menor quantidade de estômatos $\mathrm{e}$ 
cloroplastos na epiderme adaxial facilita a difusão interna, a absorção de $\mathrm{CO}_{2}$ e a passagem de luz para os tecidos subjacentes, aumentando a eficiência fotossintética. Além disso, a maior parte da transpiração foliar ocorre através do poro estomático, já que a cutícula é quase impermeável à água (Taiz \& Zeiger, 2009); dessa forma, o maior número de estômatos resulta num maior controle de perda de água por transpiração. Fato confirmado pelos os mesmos autores, que afirmam que a abertura estomática é controlada pelas células-guarda que formam os estômatos; processo que também controla a quantidade de $\mathrm{CO}_{2}$ absorvido para ser utilizado na fotossíntese.

O tipo de estômato anomocítico também foi observado nas primeiras folhas de várias outras plântulas de diferentes espécies, nestas não ocorre outro tipo de complexo estomático (Mourão et al., 2002; Cabral et al., 2004; Figuerôa et al., 2004; Souza \& Oliveira, 2004; Toledo et al., 2004; MoreiraConeglian \& Oliveira, 2006; Mussury et al., 2006; Ortolani et al., 2007), indicando que o tipo de estômato não representa um caráter que deve ser usado para diferenciação de plântulas de erva-doce, mesmo Fanh
(1990) afirmando que os tipos de estômatos podem ser usados em taxonomia vegetal de plantas adultas.

O mesofilo é heterogêneo e assimétrico com apenas uma camada de parênquima paliçádico voltada para a epiderme da face adaxial e quatro a seis camadas de parênquima lacunoso voltadas para a epiderme da face abaxial, ambos diferenciados em tecidos fotossintetizantes e de formatos semelhantes aos encontrados no cotilédone (Figura 4e).

Segundo Fahn (1990), de modo geral, o mesofilo sofre diferenciação para formar os tecidos fotossintetizantes na planta adulta e por isso, está repleto de cloroplastos. Existem depósitos de grãos de amido nas células dos parênquimas paliçádico e esponjoso, onde são encontrados de 76-85 grãos por $10 \mu \mathrm{m}$ (Figura 4c). Outras espécies também apresentam grãos de amido nas primeiras folhas das plântulas, como Hymenaea courbaril L. (Aidar et al., 2002), Hymenaea stilbocarpa Hayne (MoreiraConeglian \& Oliveira, 2006) e Fragaria ananassa Duch. (Calvete et al., 2000).

Os feixes vasculares da folha são colaterais (Figura 4f), não apresentando diferenças significativas na organização dos tecidos, quando comparada às

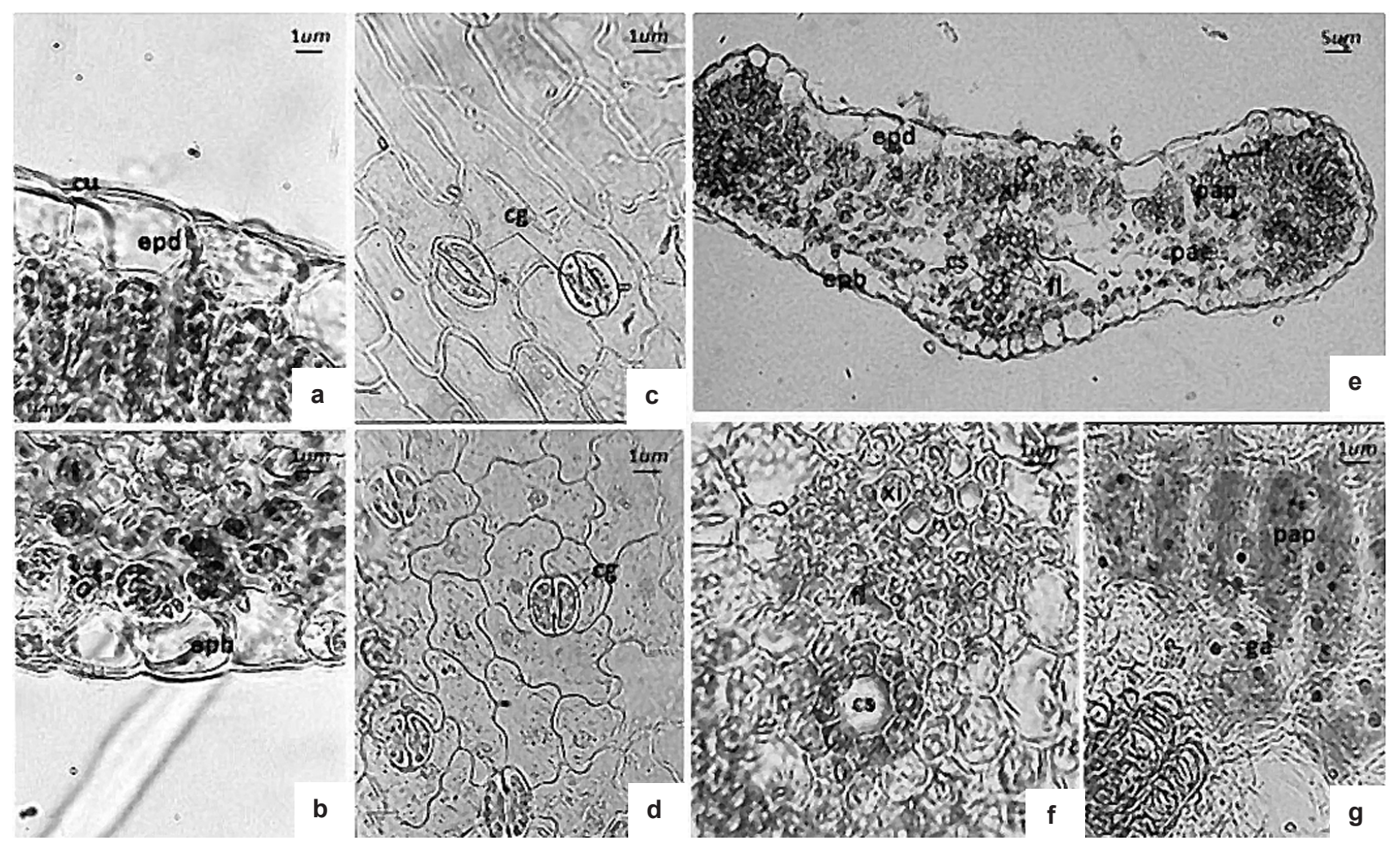

FIGURA 4. Folha da plântula de Foeniculum vulgare Mill. a. secção transversal da epiderme adaxial. b. secção paradérmica da epiderme adaxial com estômatos anomocíticos. c. secção transversal da epiderme abaxial. $\mathbf{d}$. secção paradérmica da epiderme abaxial com estômatos anomocíticos. e. secção transversal mostrando mesofilo e nervuras. f. secção transversal da nervura primária evidenciando canal secretor. g. secção transversal mostrando grãos de amido e xilema helicoidal. (cu = cutícula; epd = epiderme adaxial; epb = epiderme abaxial; cg = célulaguarda; $\mathrm{si}$ = sinuosidades; $\mathrm{pap}$ = parênquima paliçádico; $\mathrm{pae}=$ parênquima esponjoso; $\mathrm{fl}$ = floema; $\mathrm{xi}$ = xilema; cs = canal secretor; ga = grão de amido). 
do cotilédone, que possuem maior quantidade de tecidos floemático e xilemático. Esse padrão das nervuras tem a vantagem de extensibilidade e essa característica permite que os elementos de vaso se diferenciem em tecidos que estão crescendo, já que podem se alongar e continuar funcionais, levando água até as partes jovens da planta (Apezzato-da-Glória \& Carmelo-Guerreiro, 2004). Nas folhas da erva-doce, os ductos secretores também apresentam a mesma localização e o mesmo padrão celular dos encontrados nos cotilédones e segundo Sousa et al. (2005), esses tipos de ductos também estão presentes nos frutos. Na espécie em estudo, tais estruturas são responsáveis pela produção de óleos essenciais, assim como ocorre em várias Apiaceae (Simões et al., 2004).

\section{CONCLUSÃO}

A caracterização anatômica da plântula de F. vulgare auxilia na identificação da variedade e na padronização e diferenciação de plântulas normais, fornecendo informações sobre o desenvolvimento que auxiliam em estudos fisiológicos, taxonômicos e ecológicos.

\section{AGRADECIMENTO}

Ao $C N P Q$ e à FINEP pelo auxílio financeiro.

\section{REFERÊNCIA}

AIDAR, M.P.M. et al. Effect of atmospheric $\mathrm{CO}^{2}$ enrichment on the establishment of seedlings of jatobá, Hymenaea courbaril L. (Leguminosae, Caesalpinioideae). Biota Neotropica, v.2, n.1, p.1-10, 2002.

APEZZATO-DA-GLÓRIA, B.; CARMELO-GUERREIRO, S.M. Anatomia Vegetal. Viçosa: UFV, 2003. 438p.

ARIAS, R.L. El sistema secretor interno del cuerpo primário en Espeletiinae (Asteraceae). Plantula, v.3, n.3, p.129-39, 2005.

BATTILANI, J.L.; SANTIAGO, E.F.; SOUZA, A.L.T. Aspectos morfológicos de frutos, sementes e desenvolvimento de plântulas e plantas jovens de Unonopsis lindmanii Fries (Annonaceae). Acta Botânica Brasílica, v.21, n.4. p.897-907, 2007.

BERNATH, J. et al. Morphological and chemical evaluation of fennel (Foeniculum vulgare Mill.) populations of different origin. Journal of essential oil research, v.8, n.3, p.247-53, 1996.

BRASIL. Ministério da Agricultura e Reforma Agrária. Regras para análise de sementes. Brasília, 2009. 399p. CABRAL, E.L.; BARBOSA, D.C.A.; SIMABUKURO, E.A. Crescimento de plantas jovens de Tabebuia aurea (Manso) Benth. \& Hook. Moore submetidas a estresse hídrico. Acta Botânica Brasílica, v.18, p.241-51, 2004. CALVETE, E.O. et al. Avaliação do crescimento de plantas de morangueiro, durante a aclimatização ex vitro.
Horticultura Brasileira, v.18, n.3, p.188-92, 2000.

CARVALHO, N.M.; NAKAGAWA, J. Semente: ciência, tecnologia e produção. 4.ed. Jaboticabal: Funep, 2000. $588 p$.

CARMELLO-GUERREIRO, S.M.; PAOLI, A.A.S. Aspectos morfológicos e anatômicos da semente de aroeira (Myracrodruon urundeuva Fr. Allem. - Anacardiaceae), com notas sobre paquicalaza. Revista Brasileira de Sementes, v.21, n.1, p.222-8, 1999a.

CARMELLO-GUERREIRO, S.M.; PAOLI, A.A.S. Morfologia e anatomia da semente de Schinus terebinthifolius Raddi (Anacardiaceae) em desenvolvimento. Revista Brasileira de Botânica, v.22, n.1, p.91-8, 1999b.

CORREIA, M.C.R.; PINHEIRO, M.C.B.; LIMA, H.A. Produção de frutos e germinação de sementes de Anemopaegma chamberlaynii Bur. \& K. Schum. (Bignoniaceae) - Um registro de poliembrionia. Sitientibus, v.5, p.68-71, 2005.

CRESTANA, C.M.; BELTRATI, C.M. Morfologia e anatomia das sementes de Copaifera langsdorffii Desf. (Leguminosae-Caesalpinioideae). Naturalia, v.13, p.4554, 1988.

CUTTER, E.G. Anatomia vegetal - parte I: células e tecidos. 2.ed. São Paulo: Roca, 1986. 304p.

DUARTE, M.R. et al. Anatomia foliar comparada de espécies de aroeira: Myracrodruon urundeuva Allemão e Schinus terebinthifolius Raddi. Visão Acadêmica, v.10, n.1, p.18-28, 2009.

ESAU, K. Anatomy of seed plants. 2.ed. New York: Wiley, 1977. 550p.

ESAU, K. Anatomia das plantas com sementes. São Paulo: Edgard Blücher, 1998. 293p.

FAHN, A. Plant anatomy. 4.ed. Oxford: Pergamon Press, 1990. 588p.

FIGUEIROA, J.M.; BARBOSA, D.C.A.; SIMABUKURO, E.A. Crescimento de plantas jovens de Myracrodruon urundeuva Allemão (Anacardiaceae) sob diferentes regimes hídricos. Acta Botânica Brasílica, v.18, n.3, p.573-80, 2004.

GONZALEZ, A.M.; CRISTÓBAL, C.L. Ontogenia del óvulo y semilla de Sterculia striata (Sterculiaceae). Bonplandia, v.15, n.1-2, p.63-77, 2006.

HACKBART, V.C.S.; CORDAZZO, C.V. Germinação e crescimento de plântulas de Hydrocotyle bonariensis lam. (Apiaceae) em diferentes concentrações de $\mathrm{NaCl}$. Atlântica, v.29, n.2, p.85-92, 2007.

HADID, M. et al. Anatomía de la raíz de Solanum sisymbriifolium (Solanaceae). Latin American Journal of Pharmacy, v.26, n.1, p.4-10, 2007.

KITAJIMA, K. Relationship between photosynthesis and thickness of cotyledons for tropical tree species. Functional Ecology, v.6, n.5, p.582-9, 1992.

LORENZI, H.; MATOS, F.J.A. Plantas medicinais no Brasil: nativas e exóticas. 2.ed. Nova Odessa: Instituto Plantarum, 2008. 544p.

MARTINI, M.H. et al. Localization of the cotyledon reserves of Theobroma grandiflorum (Willd. ex Spreng.) K. Schum., T. subincanum Mart., T. bicolor Bonpl. and their analogies with T. cacao L. Revista Brasileira de Botânica, v.31, n.1, p.147-54, 2008.

MARTINS, M.B.G. et al. Caracterização anatômica e química da folha e do sistema radicular de Hydrocotyle umbellata (Apiaceae). Revista Brasileira de 
Farmacognosia, v.18, n.3, p.402-14, 2008.

MAUSETH, J.D. Plant Anatomy. California: The Benjamin/ Cummings Publishing Company, 1988. 560p.

MELO, M.G.G.; MENDONÇA, M.S.; MENDES, A.M. Análise morfológica de sementes, germinação e plântulas de jatobá (Hymenaea intermedia Ducke var. adenotricha (Ducke) Lee \& Lang.) (Leguminosae-caesalpinioideae). Acta Amazonica, v.34, n.1, p.9-14, 2004.

MOREIRA-CONEGLIAN, I.R.; OLIVEIRA, D.M.T. Anatomia comparada dos limbos cotiledonares e eofilares de dez espécies de Caesalpinioideae (Fabaceae). Revista Brasileira de Botânica, v.29, n.2, p.193-207, 2006.

MOTT, K.A.; GIBSON, A.C.; OLEARY, J.W. The adaptive significance of amphistomatic leaves. Plant, Cell and Environment, v.5, p.455-60, 1982.

MOURÃO, K.S.M. et al. Morfo-anatomia da plântula e do tirodentro de Trichilia catigua A. Juss., T. elegans A. Juss. e T. pallida Sw, (Meliaceae). Acta Scientiarum, v.24, p.60110, 2002.

MUSSURY, R.M. et al. Caracterização morfoanatômica de plântulas de Gomphrena elegans Mart. (Amaranthaceae). Acta Scietia Biologia Scientarum, v.28, n.2, p.87-93, 2006. OLIVEIRA, F.; AKISUE, G.; AKISUE, M.K. Farmacognosia. São Paulo: Atheneu, 2005. 412p.

ORTOLANI, F.A. et al. Morfo-anatomia de plântulas e número cromossômico de Cybistax antisyphilitica (Mart.) Mart. (Bignoniaceae). Acta Botânica Brasílica, v.22, n.2, p.345-53, 2008.

PIMENOV, M.G.; LEONOV, M.V. The asian Umbelliferae biodiversity database (Asium) with particular reference to south-west Asian taxa. Botanical Garden, v.28, p.13945, 2004.

PUTZ, N.; SUKKAU, I. Seedling establishment, bud movement, and subterranean diversity of geophilous systems in Apiaceae. Flora, v.197, n.5, p.385-93, 2004. RAMIREZ, G.C.; VALENZUELA, F.E.; MARTIN, P.C.S.
Nuevos antecedentes sobre desarrollo temprano, morfología y anatomía de las raíces proteiformes de Gevuina avellana. Agro Sur Chile, v.32, n.2, p.33-44, 2004. RAVEN, P.H.; EVERT, R.F.; EICHHORN, S.E. Biologia vegetal. 6.ed. Rio de Janeiro: Guanabara Koogan S. A., 2001. 906p.

SIMÕES, C.M.O. et al. Farmacognosia: da planta ao medicamento. Porto Alegre/Florianópolis: Editora da UFRGS/Editora da UFSC, 2004. 1104p.

SOUSA, L.A. et al. Sazonalidade dos ductos secretores e óleo essencial de Foeniculum vulgare var. vulgare Mill. (Apiaceae). Revista Brasileira de Farmacognosia, v.15, n.2, p.155-61, 2005.

SOUZA, L.A.; OLIVEIRA, J.H.G. Morfologia e anatomia das plântulas de Tabebuia avellanedae Lor. ex Griseb e T. chrysotricha (Mart. ex Dc.) Standl. (Bignoniaceae). Acta Scientiarum, v.26, n.2, p.217-26, 2004.

SOUZA, L.A.; LOPES, W.A.L.; ALMEIDA, O.J.G. Morfoanatomia da plântula e do tirodendro de Arrabidaea mutabilis Bureau \& K. Schum. (Bignoniaceae). Acta Scietia Biologia Scientarum, v.29, n.2, p.131-6, 2007. TAIZ, L.; ZEIGER, E. Fisiologia vegetal. 4. ed. Porto Alegre: Artmed, 2009. 848p.

TEIXEIRA, S.P.; GABRIELLI, A.C. Anatomia do eixo vegetativo de Dahlstedtia pinnata (Benth.) Malme e $D$. pentaphylla (Taub.) Burk. (Leguminosae, Papilionoideae). Revista Brasileira de Botânica, v.23, n.1, p.1-11, 2000. TOLEDO, A.C.O.; DUARTE, M.R.; NAKASHIMA, T. Caracterização Morfo-anatômica das Folhas de Symphytum officinale L. (Boraginaceae). Acta Farmaceutica Bonaerense, v.23, n.3, p.359-64, 2004. VON HERTWIG, I.F. Plantas aromáticas e medicinais: plantio, colheita, secagem, comercialização. 2.ed. São Paulo: Ícone, 1991. 414p.

VOGEL, E.F. Seedlings of dicotyledons. Wageningen: Pudoc, 1980. 471p. 